\title{
Procesos de ambientalización y transición agroecológica en el MST: reforma agraria popular, soberanía alimentaria y ecología política
}

\section{Lucas Henrique Pinto}

Doutor; Universidad Nacional Autónoma de México lucashpinto@gmail.com

\section{Resumen}

Buscaremos analizar en el presente artículo cómo la hegemonía del proyecto neoliberal en la economía mundial y los cambios productivos del régimen capitalista, llevaron al Movimiento de los Trabajadores Rurales Sin Tierra (MST) a incrementar también sus consignas, tanto por los avances oriundos de conflictos organizativos internos como también por su adecuación a las nuevas coyunturas hegemónicas. Problematizaremos estos procesos interrelacionando la nueva forma de pensar la reforma agraria con algunos puntos de la llamada cuestión ambiental, que no es según nuestra hipótesis, solamente una asimilación de un tema actualmente de moda, sino es la incorporación de un aspecto central en el debate sobre el actual estadio de las fuerzas productivas capitalistas y las externalidades producidas en los procesos de producción de mercancía. Cuestiones que problematizaremos en seguida a partir de entrevistas a miembros del Movimiento y sus impresiones sobre las dinámicas de tales procesos de ambientalización y transición agroecológica.

\section{Palabras clave}

Ambientalización. MST. Agroecología. Ecología política. Reforma agraria. 


\section{Introducción}

Buscaremos analizar en el presente artículo cómo la hegemonía del proyecto neoliberal $^{1}$ en la economía mundial y los cambios políticos, económicos y productivos del régimen capitalista, llevaron al Movimiento de los Trabajadores Rurales Sin Tierra de Brasil (MST) a incrementar también sus consignas, tanto por los avances oriundos de conflictos organizativos internos como también por su adecuación a las nuevas coyunturas político-sociales hegemónicas. La llamada "gran era Vargas (1930-1990) nacional-desarrollismo" (SAMPAIO, 2000) configurada por la Industrialización por Sustitución de Importaciones (ISI) y el crecimiento económico del país basado en este modelo, finalmente termina, con el ascenso al poder de Fernando Collor (1990-1992), siendo este un marco temporal central en los cambios "hacia adentro y hacia afuera" realizados por el MST que todavía estaba cerrando para aquel entonces el primer ciclo de consolidación política de la organización, fundada en 1984 (PINTO, 2015).

Con la llegada de Collor y el inicio de la implementación de las políticas neoliberales; apertura económica, privatizaciones, etc., ${ }^{2}$ la lucha por la reforma agraria también se reconfigura. Parte de tal proceso de reconfiguración tiene inicio a partir de la realización de la progresista Constitución de 1988, después de la redemocratización, donde la reforma agraria podría haber sido "hecha" legalmente -y no fue-, y el descenso en la movilización de masas que representó la pérdida electoral del frente popular que apoyaba Lula en las elecciones de 1989; en este contexto, la bandera de la reforma agraria clásica se fue reconfigurando hacia adentro del Movimiento (WAGNER; PINTO 2013).

A partir de este momento el MST empieza a hablar de una "nueva reforma agraria" que está directamente vinculada con la necesidad de derrocar el neoliberalismo, además de pensar formas de producción que no contaminen el medio ambiente. Esas formas de producción están vinculadas a las prácticas agroecológicas, y de soberanía alimentaria que el movimiento propone.

\footnotetext{
1 “El neoliberalismo es, en este sentido, en la periferia, el instrumento político que posibilita la rápida creación de las condiciones necesarias para la libre movilidad del capital en nivel mundial y el establecimiento de circuitos globales de producción y distribución. La salida de la crisis [capitalista de los '70] que instrumenta el neoliberalismo se asienta, por consiguiente, en el desmantelamiento de la intervención estatal resultante de los logros de las luchas obreras en los países centrales y de las luchas populares y de los movimiento nacionales en la periferia." (ARCEO, 2009, p. 6).

2 "Restablecida la lógica unilateral del capital, ésta se expresa en la implementación de políticas que presentan las mismas características en todos lados: tasas de interés elevadas, reducción del gastado público social, desmantelamiento de las políticas de pleno empleo y prosecución sistemática del restablecimiento de la desocupación, desgravación fiscal en beneficio de los ricos, desregulaciones, privatizaciones, etc." (AMIN, 2001, p. 4).
} 
Problematizaremos este rescate que el MST hace, interrelacionando el debate de la nueva forma de pensar la reforma agraria con algunos puntos de la llamada cuestión ambiental, que no es según nuestra hipótesis, llanamente una asimilación de un tema actualmente de moda. Por el contrario, es la incorporación de un aspecto central en el debate sobre el actual estadio de las fuerzas productivas capitalistas y las externalidades producidas en los procesos de producción de mercancía (PINTO, 2013).

Intentaremos demostrar en las próximas páginas, a partir de una breve revisión de los primeros modelos productivos adoptados por el Movimiento, hasta el proceso de incorporación de la cuestión ambiental al debate agrario hecho por el MST; que tuvo según argumentaremos a dos procesos interrelacionados: cuestiones internas y externas, que culminaron en la incorporación a partir del 4º Congreso Nacional del MST en el año 2000, con la agregación de la agroecológia como línea político-productiva a ser adoptaba y propugnada en los territorios del MST y para el campo brasileiro como un todo desde una propuesta contrahegemónica campesina y popular.

Momento en que la ecología política pasa a ser un tema central en los debates de tal movimiento, reinventándose a partir de la agroecología como parte del movimiento de ecología popular y/o justicia ambiental (MARTINEZ ALIER, 2009). Temas y cuestiones que procuraremos relatar y problematizar en seguida a partir principalmente de entrevistas a miembros del Movimiento y sus impresiones sobre las problemáticas de tales procesos de ambientalización (Lopes, 2004) y y transición agroecológica, todavía en marcha.

\section{Sustentabilidad, transgénicos y ecologismo popular}

El debate ambiental que hace el MST (aunque no se diga ambientalista) está situado en el ámbito de los conflictos ambientales (ecología política), donde las distintas concepciones y formas de apropiación del medio ambiente se contraponen. En este sentido, los terratenientes y grandes oligopolios del agronegocio se colocan como actores sociales antagónicos a las propuestas del MST. ${ }^{4}$ En los marcos de la apertura económica neoliberal, este proceso de concentración de tierras y direccionamiento productivo hacia los monocultivos generadores de commodities, se intensifica, generando una dependencia externa cada vez más

\footnotetext{
3 Para un debate más exhaustivo sobre el concepto de ambientalización frente a los procesos de conflictividad agraria véase (PINT0, 2013).

4 "Los terratenientes están comprando cada vez más tierra. Apenas 15 mil hacendados -un barrio chico de Río de Janeiroposeen 98 millones de hectáreas, el equivalente a 4 veces el Estado de São Paulo. Muchos ni conocen las haciendas. Son banqueros e industriales." (STEDILE, 2010, doc, no paginado, nuestra traducción).
} 
grande y una creciente contaminación ambiental vinculadas a tal modelo productivo, lo que en partes influenció la entrada del MST en los debates de la cuestión ambiental.

\begin{abstract}
De modo general, la cuestión de los transgénicos despunta, para el MST, en medio de la reflexión sobre la cuestión ambiental y la crítica a la matriz tecnológica productivista y economicista-responsable por la exclusión social. Una de las preocupaciones es la necesidad de implementación, junto a los asentamientos rurales, de una nueva matriz tecnológica y productiva y la preservación socioambiental de la sociedad brasileña. Por el rescate de la producción orgánica en oposición a la producción convencional y por la institucionalización de nuevas y más adecuadas líneas tecnológicas, reivindican. Según los lideres, la lucha del Movimiento es fundamentalmente una lucha por la preservación de la naturaleza y de la vida-una vida con dignidad, afirman. Y la crítica a los transgénico es parte de una lucha mayor: por la tierra y la reforma agraria; por la garantía de acceso a la habitación, infraestructura, créditos, asistencia técnica, condiciones de comercialización de la producción, educación, salud; por un nuevo modelo de desarrollo y también por la transformación de la sociedad. (BRUNO, 2008, p. 91, nuestra traducción).
\end{abstract}

Por lo tanto el MST se coloca también crítico a las "salidas ecológicamente sostenibles" (ideología del desarrollo sustentable) (PINTO, 2011) pensadas por el gran capital, bajo la lógica de la adecuación económico-ambiental de los medios de producción capitalistas, planteados por la ecoeficiencia y sus productos "verdes". En ese sentido es interesante la no compatibilidad entre los planteos y posicionamientos de un movimiento social que se dice campesino, reconociéndose como miembro de una clase trabajadora, en el marco de una sociedad dividida asimétricamente en diferentes clases sociales, en oposición a la idea de un ambientalismo: supraclasista, consensualita, actualmente discutida y adoptada por distintos movimientos ecologistas y por partes significativas de la academia, medios de comunicaciones, ONGs etc., como comentado por Acselrald:

Desde el inicio de los años de 1990, el movimiento ambientalista en Brasil estuvo confrontado a una lectura sociológica de si propio según la cual la diversidad interna del ambientalismo exprimía la adhesión cooperativa gradualmente crecente de los diferentes 'sectores' de un mismo ambientalismo, definido, por algunos autores, como 'multisectorial' [...]. Según este análisis, el movimiento ambientalista seria caracterizado por su carácter transclasista y el fenómeno del ecologismo resultaría de la emergencia gradual de múltiplos segmentos de la sociedad compartiendo una misma visión de mundo dita 'ambientalista'. Así, al que llamaban de un 'ambientalismo propiamente dicho', sumariase un ambientalismo académico, uno empresarial, uno gubernamental, un religioso, etc. Decían entonces los representantes de este pensamiento que no se debería considerar el movimiento ambientalista como un movimiento social stricto sensu, pero como 'un movimiento histórico, por ser multisectorial' y por 'volcarse para valores universales, que ultrapasan las fronteras de clase, 
raza, edad y sexo' (SILVA-SÁNCHEZ, 2000, p. 50-525 apud ACSELRAD, 2012, p. 40, nuestra traducción).

$[\ldots]$

La cuestión ambiental tendría, en esta óptica 'la capacidad de obtener resonancia entre los diferentes grupos sociales, promoviendo una especie de 'consenso' cuanto a la urgencia de medidas que visan la preservación del medio ambiente.' (SILVA-SÁNCHEZ, 2000, p. 546 apud ACSELRAD, 2012, p. 40, nuestra traducción).

La asimilación del debate ambiental por parte del MST viene a cuestionar mucho de lo citado arriba, pues él se reconoce como un movimiento social de campesinos y trabajadores pobres, y plantea una visión de mundo alternativa al capitalismo como sistema y concretamente al agronegocio y la agricultura convencional transgénica como modos y medios de producción de alimentos en el campo, debates que proseguiremos en seguida.

\section{Problemas en la implementación del modelo productivo de la agricultura convencional}

En lo que concierne a las cuestiones internas parece ser casi una unanimidad entre los investigadores del tema e incluso entre algunos militantes del Movimiento, que los límites del paradigma de producción convencional adoptado inicialmente por el MST, presentó su máxima manifestación en los problemas expresos por el modelo de Cooperación Productiva impulsado a partir del $2^{\circ}$ Congreso Nacional del Movimiento realizado en mayo de 1990, que tuvo en las $\mathrm{CPA}^{7}$ la principal materialización de tal proyecto productivo (BORGES, 2009, p. 4). Durante la fase de gestación del MST de 1980 a 1985 la producción en los asentamientos era básicamente individual, por no estar todavía conformado como Movimiento no habían sido debatidos orgánicamente las formas de cooperación y el modelo productivo a ser adoptado por el MST en sus territorios (MORISSAWA, 2008).

Así pasado el período inicial de organización a partir del 1ํㅡㄹ Congreso Nacional del Movimiento en 1985, se realizó en 1986 un Encuentro nacional de Asentados donde incluso fue debatido sobre la posible creación de otro movimiento solamente conformado por los campesinos que ya estuviesen en la tierra (asentados). Posteriormente a lo largo del debate

\footnotetext{
5 SILVA-SÁNCHEZ, Solange S. Cidadania Ambiental: novos direitos no Brasil. São Paulo: Humanitas e Annablume, 2000. p.50-52

${ }^{6}$ SILVA-SÁNCHEZ, Solange S. Cidadania Ambiental: novos direitos no Brasil. São Paulo: Humanitas e Annablume, 2000. p. 54

7 "Es un tipo de cooperativa en que los factores de producción (la tierra, el trabajo y el capital) son administrados colectivamente. Su propiedad y su producción son sociales, pues los dueños son los trabajadores y la sobras son repartidas entre sí conforme el trabajo aportado por cada uno. En general, ésta cooperativa se restringe a un pequeño número de familias variando de 10 a 60." (MOVIMENTO DOS TRABALHADORES..., 2009, doc. electrónico, nuestra traducción).
} 
se decide por mantener la unidad del MST (acampados "sin tierra" y asentados "con tierra") y se crea la Comisión Nacional de los Asentados, que tenía el objetivo de diagnosticar los principales problemas que vivían los asentados, otro objetivo fue debatir junto al Ministerio de la Reforma y Desarrollo Agrario (MIRAD, actualmente Ministerio del Desarrollo Agrario (MDA), en Brasilia, la necesidad de crédito para los asentados, discusión que posteriormente llegaría a concretizarse en el Programa de Crédito Especial para la Reforma Agraria (PROCERA). La comisión se transformó en Sector de los Asentados, que se dedicó a la formación de distintas asociaciones y cooperativas de producción, sin embargo, los resultados de éste intento no fueron satisfactorios y hacia fines de los años de 1980 principios de los '90 el Movimiento pasa a investir fuertemente en el cooperativismo (MORISSAWA, 2008).

Los objetivos del cooperativismo entonces implantados en detrimento del anterior proceso de asociación ${ }^{8}$ y como una manera de compleméntalo- y/o supéralo- trajo una óptica productivista de inserción en el mercado, que tuvo como características predominantes la reproducción- en partes- del paradigma de la Revolución Verde en los mismo espacios del MST. "Para alcanzar índices de productividad con las exigencias del mercado, las cooperativas tuvieron que invertir en insumos químicos, máquinas y equipos compatibles con las orientaciones modernas de las prácticas agrícolas." (BORGES, 2009, p. 9). Tal proceso fue iniciado teniendo en vista la perdida de los subsidios públicos que el gobierno de Collor retiró al llegar al poder, por consecuencia de los cambios en las políticas macro económicas antes mencionados:

Frente de una política económica y agrícola que penaliza el pequeño agricultor, el asentado no puede contentarse con la conquista de la tierra. Hay la necesidad de encontrar medios que le posibiliten tener acceso a recursos financieros y técnicos, condiciones favorables de producción y comercialización; acceso a las técnicas de producción más desarrolladas y a la mecanización. Recursos éstos hoy, solamente al alcance de los grandes propietarios. Es para proporcionar esas condiciones que estamos implantando la organización de cooperativas en nuestros asentamientos. [...] Solamente así estaremos aptos a hacer frente a esa acelerada política entreguista del presidente Collor, sumiso a los intereses internacionales y a los latifundistas, cada vez más protegidos por aparatos represivos. (JORNAL SEM TERRA, 1991, p. $2^{9}$ apud BORGES, 2009, p. 5, nuestra traducción).

\footnotetext{
8 "Existen varios tipos de asociación: de adquisición de animales, maquinas o implementos agrícolas; de comercialización (compra y venta de productos agropecuarios); [...] almacenamiento molinos etc. En general la producción ocurre en lote familiar y la asociación presta algún servicio de interese común. En algunos casos, ella sirve solamente para la representación política de los asentados." (MOVIMENTO DOS TRABALHADORES..., 2009, doc. electrónico, nuestra traducción).

${ }^{9}$ Jornal dos Trabalhadores Rurais Sem Terra. São Paulo, v. 10, n. 101, 1991.
} 
Así el Movimiento defendía y planteaba las directrices de su forma de cooperativismo para enfrentar las políticas del gobierno Collor, por ende después de la implementación a nivel local de las CPA, a partir de la consumación del Sistema Cooperativista de los Asentados (SAC) se organizó la estructura de funcionamiento del sistema cooperativo en los niveles provincial y nacional, teniendo como objetivo centralizar nacionalmente el modo de producción adoptado por el Movimiento y reproducido a partir de la CPA. Además estaban las Centrales Cooperativas de los Asentamientos (CCA) a nivel estadual (provincial) y en mayo de 1992 es fundada la Confederación de las Cooperativas de la Reforma Agraria de Brasil (CONCRAB) (MORISSAWA, 2008; BORGES, 2009).

La creación de las CPA, según autores cercanos al Movimiento (CARVALHO, 2011), representaba un anhelo organizativo que en tesis superaría a las precedentes formas de asociativismo antes vigentes, que primaban por la producción individual, serían las CPA por lo tanto una respuesta también a la coyuntura política entonces vivida:

La mayoría de las 49 CPA, inspiradas en un tipo de cooperativa cubana, se constituyó como una forma de resistencia política y, al mismo tiempo, de ensayo para la superación del individualismo económico. Fueron consecuencia de dos factores coyunturales, aunque contradictorios: la fuerte represión económica, política, ideológica y policial desencadenada contra el MST durante el gobierno de Collor de Mello (1990-1992), cuando el MST sufrió la más fuerte persecución política y policial, y exigió retrocesos defensivos en la lucha por la tierra para evitar su exterminio. Uno de estos tipos de refugio creados fueron las CPA. El otro factor fue la necesidad de enfrentar políticamente, mediante una forma de organización de la producción más compleja, la situación de oligopolista y oligopsónica de los mercados de insumos y productos agropecuarios, teniendo en cuenta la completa liberación de los mercados por la eliminación de mecanismos como las adquisiciones del gobierno federal y las cantidades de mercancía disponibles (stocks) reguladoras, impuesta a la población a partir del gobierno de Collor. Las CPA y, posteriormente las CPS [Cooperativa de Prestación de Servicios] fueron respuestas a situaciones concretas vividas por los trabajadores rurales asentados sin tierra (CARVALHO, 2011, p. 195).

La implementación de las cooperativas (CPA) trajo diversos conflictos internos en el Movimiento por estar englobada en una propuesta que implicaba en la ejecución de un sistema de división de las tierras y modos de pensar la producción y la organización social de ésta, a partir de un paradigma colectivizado y centralizado (NAVARRO, 2011). Tal perspectiva político-organizacional, generó muchos conflictos entre los campesinos que querían por decisión política y simbólica subjetivas, no producir colectivamente, resguardados en una “'[...] memoria social' estando referida a las trayectorias de vida y a los modos de concebir el trabajo: 'Tiene aquel que le gusta conducir las cosas él mismo, no le gusta ser mandado'. [...] 
'siempre tuve medio que pensando individual'." (SCHREINER, 2012, p. 5, nuestra traducción). Pronto parte de los conflictos en la instalación de las CPA estuvieron vinculados a la resistencia que se daba por las distintas convicciones políticas en partes de la base (divergiendo de las deliberaciones nacionales), y también por las características de las propuestas que no llevaban- generalmente- en cuenta las distintas formas e imaginarios políticoorganizativos, anteriormente vivenciados por la base social antes de su entrada al MST: "La CPA es vista como forma de organización social superior, denotando estadio más avanzado en la consciencia social y política." (SCHREINER, 2012, p. 8, nuestra traducción).

Otro de los problemas enfrentados estuvieron vinculados a la matriz tecnológica adoptada, que se proponía a disputar partes del mercado con las multinacionales y terminaba por ello, a reproducir el modo de producción convencional basado en el gran uso de agroquímicos, monocultivos, semillas hibridas etc., y en la producción de commodities (principalmente soja), utilizando los varios recursos disponibles en el mercado de la agricultura convencional para adentrar al circuito mercantil (BORGES, 2009, p. 10). Lo que económicamente también pasó a representar un reto al desarrollo de tal modelo por un movimiento campesino:

[...] las primeras experiencias de la forma constructiva colectivista comenzaban a presentar resultados económicos negativos, lo que inducia algunos analistas rigorosos a reflexionaren sobre la inadecuación del modelo de agricultura empresarial- orientado para la intensificación del capital y a la reducción de la mano de obra, que era la base de la referida producción colectiva, las condiciones objetivas de los asentamientos-, de baja capacidad de inversiones y gran disponibilidad de mano de obra ( ${ }^{\prime}$ INCAO; ROY, 1995, p. $36^{10}$ apud BORGES, 2009, p. 10, nuestra traducción).

Luego, con problemas en las esferas política, económica y posteriormente también ambiental, ya en 1994 el Movimiento procura reformular su propuesta cooperativista, ${ }^{11}$ ampliando la misma a otras variables de cooperación, aunque manteniendo el hincapié en la colectivización ahora no necesariamente total, abriéndose así el proceso decisorio de cómo será la cooperación (producción) a los propios asentados, basados en las circunstancias productivas y políticas de cada asentamiento.

\footnotetext{
10 D’INCAO, Maria C.; ROY Gérard. Nós, cidadãos: aprendendo e ensinando a democracia. Rio de Janeiro: Paz e Terra, 1995. p. 36

11 "El documento 'La crisis de las cooperativas de Producción Agropecuaria' (Texto de Paulo Cerioli y Pedro Cristoffoli) es representativo del debate de la reformulación de la propuesta de cooperación del MST.” (SCHEREINER, 2012, p. 5, nuestra traducción).
} 
Entre esas diversas formas, se propuso la cooperativa de comercialización. Esa cooperativa resguarda la concepción y modo social de producción de los agricultores, centrado en la tierra y el trabajo familiar, con inserción en el mercado. (SCHREINER, 2012, p. 4, nuestra traducción).

Una cuestión central que la "crisis del cooperativismo" dejó patente en el seno del Movimiento fueron los límites y contradicciones que la asimilación del modo de producción convencional, que anteriormente había ayudado en la expulsión de muchos de éstos mismos campesinos de la tierra, era repetido- paradójicamente-en el intento de competir con el mercado agroalimentario en las mismas bases productivas impuestas por las multinacionales.

\section{Dinámicas de los procesos de ambientalización y transición agroecológica}

Para intentar entender de forma inicial y breve, también por las limitaciones de espacio del presente artículo, las dinámicas de los procesos de ambientalización, seleccionamos algunos relatos de militantes del MST, desde entrevistas realizadas donde se demuestran los diferentes aspectos presentes en las dinámicas de ambientalización y construcción de la idea/práctica de transición agroecologia dentro de los territorios productivos del Movimiento, frente a la anteriormente descrita crisis político-productiva.

La primera entrevista analizada fue realizada con el miembro del Sector de Producción, Cooperación y Medio Ambiente del MST, José Maria Tardim, técnico agropecuario de formación que trabajó en la extensión rural desde la década de 1980, en el estado de Paraná. José María entró para el MST en 2005 formando parte del equipo político pedagógico de la Escuela Latinoamericana de Agroecología (ELAA), ya como parte del proceso de implementación y transición agroecológica realizada por el Movimiento en el ámbito de La Vía Campesina. ${ }^{12}$ La lectura que hace José María sobre su proceso de acercamiento a la agroecología hacia principios de la década de 1990, es interesante para entender lo que pasaba no sólo con el MST, sino también con otros sectores del campesinado brasileño y personal técnico que auxiliaba a los campesinos en sus tareas productivas.

12 Por una descripción más amplia y problematizada sobre el origen y rol de La Vía Campesina Internacional véase (PINTO, 2011b). 
En esta trayectoria de 1981 hasta el período, para situar mi persona no el proceso como un todo, de 1981 hasta ese periodo en 1993, nosotros llegamos a un límite del punto de vista de la organización campesina, porque por más que nosotros desenvolvíamos un cierto grado de formación de consciencia de la organización y de la lucha política, del punto de vista práctico nuestra perspectiva era la modernización de la agricultura campesina, era apropiarnos de las políticas públicas gubernamentales, para implementar la Revolución Verde en el campesinado. Y nosotros llegamos en un límite con eso allí... inicio de los años '90 nosotros ya nos agotamos del punto de vista político justamente porque nuestra política, nuestra lucha política se agotaba en apropiarse de los mecanismos de expropiación nuestra misma, a través de la implementación de los procesos tecnológicos del propio capital. Entonces nosotros nos agotamos en esta lucha, solo que no entendíamos claramente lo que estaba pasando con nosotros, y percibíamos entonces por la intuición que teníamos que encontrar otro camino, nosotros no sabíamos cuál. Del punto de vista político también no estaba claro, porque nos faltaba el conocimiento filosófico-(materialismo dialéctico) [...] Nuestra formación era materialista hasta cierto sentido, pero predominantemente a partir de la Teología de la Liberación. Entonces esta matriz no nos permitía elucidar los problemas que nosotros estábamos enfrentando. Esto es fines de los ' 80 inicios de los ‘ 90 , cuando nosotros sentimos en la propia estructura, de nuestra existencia política, un agotamiento. (J.M.Tardim. entrevista realizada el $27 / 07 / 2010$.)

Con efecto, más allá de los limites económicos y políticos del intento de adoptar/reproducir el productivismo hacia dentro del MST, la adopción de la agroecología ${ }^{13}$ como bandera política nacional del Movimiento y no sólo como manifestación de experiencias puntuales, va ser fuertemente influenciada por distintas crisis productivas vinculadas a los bajos precios de determinados artículos producidos en los asentamientos. La caída de los precios estaban a su vez directamente vinculadas al ascenso del agronegocio ${ }^{14}$ a partir de la modernización del agro, procesos visualizados estratégicamente con la llegada de los productos transgénicos.

Por consiguiente, hasta el periodo en cuestión (año 2000), sacando a algunas vagas referencias a la preservación de la "naturaleza", "cuidado con los recursos naturales" etc., desde los primeros documentos del Movimiento en la década de 1980, no hay una real decisión política en adoptar la agroecología como modelo productivo en el campo, en oposición

\footnotetext{
${ }^{13}$ En la plataforma que el movimiento llama de "Una Reforma Agraria Popular", la agroecología entra como uno de los ejes de tal proyecto: "Adoptar la agroecología como a matriz predominante de técnicas de producción agrícola también es un paso importante para que posamos aumentar la productividad del trabajo en el cultivo en equilibrio con la naturaleza. Deja de usar venenos agrícolas y otras prácticas predadoras, que desequilibran el medio ambiente, es fundamental para la calidad de vida de todo el pueblo." (MOVIMENTO DOS TRABALHADORES..., 2010, nuestra traducción).

${ }^{14}$ El Agronegocio representaría el ascenso de un nuevo modelo de producción agrícola, a partir principalmente de la apertura neoliberal, representado por una alta capitalización y transnacionalización de la agricultura enmarcada en una alianza entre el capital financiero (banqueros), grandes productores de tierra (latifundistas) y corporaciones transnacionales de semillas, insumos químicos etc.
} 
al modelo convencional implementado desde la década de 1960 por la Revolución Verde, ni mismo una abierta decisión por dialogar con las demandas ambientalistas clásicas. ${ }^{15}$

La decisión de adentrar a los debates ambientales como parte de su estrategia político-productiva a nivel nacional, sólo quedaría manifiesta, por lo tanto, en las deliberaciones políticas del 4ํㅡㄹ Congreso Nacional del año 2000. Para muchos la palabra agroecología ${ }^{16}$ no era ni conocida como confiesa Tardim, hoy director pedagógico de la ELAA y uno de los más importantes referentes del tema dentro de La Vía Campesina a nivel Latinoamericano, aclarando el primer contacto que tuvo con el concepto hacia 1993, cuando de su participación en un curso ministrado por una ONG ambientalista que promovía la agroecología en Brasil: “[...] la palabra agroecología ella no existía ni mismo en mi vocabulario. [...] [La conocí] por intermedio de la llegada de la ONG (ASPTA). En verdad del conjunto de los técnicos y campesinos de la región sudeste de Paraná, esta palabra era ignorada" (J. M. Tardim. Entrevista realizada el 27/07/2010).

Una cuestión también importante para la continua asimilación por parte del MST de las cuestiones vinculadas primeramente a la producción orgánica, y posteriormente a la agroecología, fue el hecho de que a diferencia del agronegocio que practica una agricultura "sin agricultores" con un elevado uso de maquinarias en las plantaciones, utilizando solamente el mínimo de mano de obra asalariada en las tareas que no pueden ser mecanizadas. Los campesinos vinculados al Movimiento, diferentemente, están casi siempre en unidades productivas organizadas con división colectiva del trabajo entre grupos de asentados y/o en núcleos familiares donde: amigos cercanos, padres, hijos, familiares en general, son los responsables por aplicación de los venenos, cuando estos asentados siguen el patrón agrícola convencional de la Revolución Verde. Luego, los mismos tienen que señalar en tierra fumigaciones aéreas, hacer el cuidado de las plantaciones in locus sufriendo ellos mismos los efectos inmediatos de tal modelo productivo. A diferencia de los productores vinculados al agronegocio que en muchos casos ni viven en el campo.

\footnotetext{
15 Incluso parte de la tradición ambientalista estricto sensu objetaba y/o no creía en una apertura mayor del Movimiento hacia los temas ambientales de forma programática: “[...] sabemos que el MST no es un movimiento que pretende levantar las banderas ecologista o ambientalista [...] al contrario, veremos [...] como nunca expresó identificación ni simpatía con tales movimientos. No obstante, por una serie de razones, políticas y culturales, con una progresiva maduración y a través de una óptica bastante singular, el mismo incorpora en su agenda de lucha y en sus reivindicaciones algunos de los temas muy caros a los ecoambientalistas." (GIULIANI, 1997, p. 71 apud COSTA NETO; CANAVESI, 2002, p. 215).

GIULIANI, Gian Mario. 0 movimento dos trabalhadores rurais Sem Terra e a questão ecológica. Revista da Universidade Rural Série Ciências Humanas, Seropédica, v. 19/21, n.1/2, p. 68-84, 1997.

${ }^{16}$ El debate sobre la Agroecología para el MST entraría en que: “La reorganización de la producción agrícola brasilera deba venir acompañada por un nuevo sistema de planeamiento y modelo tecnológico orientado en el enfoque ecológico y participativo, adecuado a la reforma agraria, las unidades campesinas de producción, que busque aumentar la productividad de la tierra y la productividad del trabajo, en equilibrio con el medio ambiente, preservando la producción de alimentos saludables." (MOVIMENTO DOS TRABALHADORES..., 2010, nuestra traducción).
} 
La entrada del MST, o primeramente de algunos asentamientos y sectores del Movimiento a la producción orgánica y posteriormente la politización de ésta decisión frente la adopción de la agroecológica como matriz productiva, puede ser mejor entendida en el relato de Rodrigo Lopes, uno de los referentes en el debate ambiental del MST, y también en el ámbito continental de La Vía Campesina, que presenció en las dos décadas que pertenece al Movimiento, el avance interno del tema y las circunstancias que determinaron, principalmente en el estado del Rio Grande do Sul, ${ }^{17}$ la adopción de la producción orgánica:

En aquél periodo [cuando entré al MST en 1992] me acuerdo en uno de los primeros encuentros que participe, del Movimiento, que era una cosa muy embrionaria [el debate ambiental], habían personas que hacían intervenciones en reuniones, en encuentros ya intentando pautar esa discusión, pero todavía era mucho más por una razón de ideal, del idealismo que de experiencias concretas. El debate comienza a avanzar más en el campo de la preocupación ambiental a partir de la segunda mitad de la década de 1990, con algunas experiencias puntuales, yo voy hablar a partir de Rio Grande do Sul no me siento autorizado en hablar sobre todo el país, pero sí de la región donde vivo. Comienza a partir de la segunda mitad de la década de los ' 90 con algunas experiencias puntuales de producción orgánica de substitución de insumos, no en una visión del ambiente como un todo. Entonces va lentamente avanzando a partir de la virada de 1999 para 2000 es que en mi asentamiento, yo soy asentando en una región productora de arroz, en que hubo un momento de crisis del modelo agrícola tradicional. Ocurrió un proceso general de falencia de los agricultores, de los productores tradicionales, y de los agricultores familiares, particularmente, nosotros los asentados tuvimos un problema de sobrevivencia inmediata, el gran productor él va a la quiebra, pero él puede siempre renegociar la deuda con el banco, el agricultor familiar, el campesino si él entra en quiebre pierde la tierra es expulsado. [...] (Rodrigo Lopes. Entrevista realizada el 29/07/2010)

Rodrigo Lopes sigue en el mismo párrafo con los relatos concernientes al proceso de transición agroecológica realizados en el proceso de su asentamiento. Ejemplo éste muy emblemático del proceso general de ambientalización vivido por distintos territorios del Movimiento a nivel nacional, en sus distintas y variadas manifestaciones en cada realidad y región específica del país, consecuentemente:

Entonces acumulase dos procesos... En aquél periodo de 1998, 1999 hubo un quiebre generalizado en la producción de arroz [...]. Había gente y yo me incluyo entre ellos, que ya defendíamos esa cuestión de la producción

\footnotetext{
${ }^{17}$ Adoptamos las experiencias puntuales del Rio Grande do Sul como ejemplos del proceso de ambientalización y transición agroecológica del MST, siendo las experiencias en tales territorios (sur de Brasil), donde el Movimiento ensaya algunas prácticas que posteriormente son ampliadas a más estados de Brasil, como comentado por Navarro: "[...] las ilustraciones empíricas extraídas de la historia del MST en Rio Grande do Sul (o en el sur del país) son ampliamente significativas y representativas como para ser, con frecuencia, generalizadas para el resto del país. Originada en el Brasil meridional, la organización de los sin tierra tiene en Rio Grande do Sul su más antigua y firme filial. Prácticamente todas las iniciativas estructuradas por el MST fueron probadas primeramente en este estado, que ha servido de campo de experimentación para las diferentes iniciativas promovidas por la organización a lo largo del tiempo, y después repetidas nacionalmente." (NAVARRO, 2011, p. 150).
} 
agroecológica desde antes, sin embargo esa crisis crea una situación propicia para hacer un trabajo más serio y más amplio sobre este tema. Aunque es importante frisar que en ese período todavía no se tenía una preocupación con el ambiente, era más bien una preocupación de sustitución de insumos en la agricultura, entonces comenzó por allí. En mi asentamiento en particular fue una jugada de riesgo, porque nosotros en la época producíamos convencional, y allá hay un factor que pesa bastante para nosotros, el principal elemento que más influenció en la época en el debate, más que la sustitución de insumos [agroquímicos convencionales por insumos orgánicos] fue el elemento de la salud. Nosotros tuvimos mucha gente hospitalizada en aquél periodo de 1998/1999, por el uso de agrotoxicos...de veneno. Dentro del propio asentamiento, nosotros contratábamos una empresa de aviación para fumigar el veneno, en la época todavía no había el tal del GPS, era todo 'bandereando' como nosotros decíamos, una persona con una bandera roja allá en el medio del campo señalizando... Ésta persona ella se envenenaba directamente, pasaba todo el día mojada de veneno, nosotros llegamos a un punto donde nadie más quería hacer, nadie más aceptaba hacer esto, todos estaban enfermos. Entonces también influenció éste elemento en el proceso de conversión. El personal de la asistencia técnica, nuestros agrónomos, orientaban en la época los asentados para hacer pequeñas experiencias, si tú tienes 10 hectáreas de arroz, hagas una hectárea de arroz orgánico para ir probando y dominando la técnica. (Rodrigo Lopes. Entrevista realizada el 29/07/2010)

A partir de aquí Rodrigo describe un poco de las divergencias que habían entre la base asentada del MST dispuesta a implementar los cultivos orgánicos y partes de los técnicos del Sector Productivo todavía incrédulos y recelosos sobre tal propuesta productiva:

Entonces esa técnica recomendó que nuestra cooperativa hiciera 13 hectáreas y nosotros decidimos que no, nosotros vamos hacer todo de una sola vez. Entonces hicimos en aquél año 140 hectáreas de arroz orgánico, la sustitución de insumos, en verdad sólo sustituimos los insumos y alternamos la fertilización. Era una jugada de riesgo, nosotros podríamos entrar en quiebra aquél año, fue una decisión política interna contraria a la orientación de la asistencia técnica del Movimiento, y fue una jugada de riesgo, pero salió bien y en seguida otras familias comenzaron a hacer también. Y mismo otras cooperativas que tenían experiencias de 3 hectáreas y lo que quedaba de labranza convencional, comenzaron a adoptar también...fue evolucionando y hoy allá en nuestra región de Porto Alegre son más de 300 asentados [familias] produciendo ecológicamente ya con el proceso de certificación a más de 10 años, el debate ya ultrapasó la cuestión de la mera sustitución de insumos, la experiencia fue enseñando y el propio Movimiento fue madurando con los experimentos, con la inserción de otras regiones donde el Movimiento está...Hoy tenemos una noción bien más clara, a respecto de la cuestión ambiental que extrapola la cuestión de 'yo sustituyó los insumos en mi producción y está todo solucionado', uno tiene elementos geopolíticos de la acción de las corporaciones que son mucho mayores que acabaron transformándose para nosotros. No sólo en banderas, pero en estrategias de lucha, hoy ya no da más para separar nuestra lectura de la cuestión ambiental, la protección del ambiente de la acción de las corporaciones, particularmente en la agricultura. [...] la celulosa los agrocombustibles...Ellos tienen un impacto 
directo en el ambiente. [... .... Entonces es la lectura que nosotros tenemos, nosotros no separamos el debate ambiental... para nosotros no pasa sólo, aunque sea una parte, pero no pasa sólo por mi práctica cotidiana de usar o no usar plástico, usar o no usar bolsa reciclada, mucha gente se fija sólo a esto, nosotros entendemos que es un elemento, pero no es definitivamente el elemento más importante, él elemento más importante es el enfrentamiento a las corporaciones. (Rodrigo Lopes. Entrevista realizada el 29/07/2010)

Luego, como manifestado por Rodrigo, las experiencias concretas de acercamiento al debate ambiental, más allá de las deliberaciones nacionales, surgían previamente de las necesidades materiales vividas en algunos asentamientos, consecuencia de las crisis agrícolas provocadas por las políticas neoliberales y los efectos nocivos del uso de los agrotóxicos inherente al modelo convencional de agricultura.

Por lo tanto, más allá de una supuesta conciencia ambiental contemporánea posmaterialista factores vinculados directamente a la sobrevivencia; económica y física de los campesinos, van a ser condicionantes centrales en la asimilación (deliberada o no) de una preocupación ambiental creciente hacia el interior del MST, y programáticamente en las definiciones de sus banderas políticas. La adopción de la agroecología hace parte de un proceso continuo de reformulación y de ampliación de las demandas internas del Movimiento, que saliendo de la inicial consigna de lucha por la tierra viene ampliando y reformulando sus banderas y prioridades organizativas desde 1984:

Es en medio a este proceso que el Movimiento va evolucionando, y nuestras tácticas de lucha van evolucionando a lo largo de ello, en el inicio nosotros teníamos una noción ingenua de que bastaba la tierra para solucionar nuestros problemas, asienta a las familias y ya está hecho vamos ser felices para el resto de nuestras vidas. Es ahí que comenzamos a aprender a lo largo de la historia que habían otros elementos, el primero, que nosotros aprendemos fue de la educación, la necesidad de educación, nuestra lucha por tener escuela, por tener profesores, escuela en el medio rural de calidad que atendiese a nuestra realidad... Hubo un momento que comenzamos a organizar las cooperativas, también en la imaginación que las cooperativas iban nos permitir resolver nuestros problemas de sobrevivencia, aprendemos que ellas son una herramienta importante, basta comparar los asentados que son cooperativizados y los que no son para comparar el nivel de vida, son herramientas importantísimas, pero descubrimos también que ellas no son la solución para los problemas, que la lucha está bien arriba de ello. (Rodrigo Lopes. Entrevista realizada el 29/07/2010)

Las definiciones orgánicas sobre el tema ambiental van saliendo inicialmente desde el interior de las bases, en un proceso gradual que tiene mayor proyección nacional y visibilidad externa a partir del año 2000. No obstante, el tema ya venía a lo largo de los años de 
1990 siendo gestado por las "nuevas generaciones" de asentados y técnicos. Quienes empezaban a debatir sobre la necesidad de cambiar el modelo convencional, y partir para una nueva matriz productiva, menos degradante hacia el ecosistema y a los mismos productores:

[...] adentro del MST ese debate [ambiental] ya había empezado en la década de los '90, en el inicio era muy embrionario de los militantes jóvenes y de los agrónomos, la gran fuente de militantes en el área técnica es la FEAB [Federación Brasilera de Estudiantes de Agronomía], ella siempre fue una fuente de cuadros para el Movimiento. En el inicio era medio así el personal de la agronomía y los militantes más jóvenes, los más viejos veían con escepticismo. Yo digo así hoy, estoy con 40 años, tengo 18 años de militancia en la espalda, pero en aquella época yo tenía 20 años, entonces era una cosa así más de mi generación ese debate. La gente decía 'vamos hacer, vamos hacer ecológico sí', pero no hacía. Cuando mi generación fue asentada en el inicio por razones de sobrevivencia continuamos reproduciendo el modelo [convencional] y lentamente comienza a aparecer las primeras experiencias puntuales, pequeñitas, una 'experienciazita' de una hectárea de arroz aquí, un productor de leche empieza una experiencia allá... Pero ella [agricultura orgánica] empieza a crecer mismo cuando hay una ruptura, el movimiento de acomodación del capitalismo de reorganización del capitalismo, precisaba eliminar algunos productores para concentrar más tierras, en el caso del arroz fue lo que paso." (Rodrigo Lopes. Entrevista realizada el 29/07/2010)

También un sector no tan joven así de sin tierras, todavía adeptos de la agricultura tradicional, anterior a la revolución verde, por consiguiente menos dependiente de los agroquímicos y fertilizantes externos (además de contaminantes, muy caros), hacen parte del proceso que va gradualmente definiendo la agroecología como meta productiva para las áreas del MST.

La participación del Movimiento en los espacios de La Vía Campesina también va, concomitante al proceso interno, influenciando las decisiones del MST. En esa parte de su entrevista, José María Tardim relata la influencia de la tradición campesina anterior a la revolución verde en los debates agroecológicos, que viene a complementar los empeños oriundos de las nuevas generaciones. Otra marca del proceso fueron las dificultades materiales en se conseguir mano de obra técnica preparada para auxiliar en la producción agroecológica, lo que obliga en partes a una toma de posición estructural y estratégica del Movimiento, en conjunto a las otras organizaciones de La Vía Campesina, frente la necesidad de formación de técnicos agroecológicos desde sus propias filas.

Entonces hay varias experiencias locales sucediéndose, pero también en el interior del MST, otro sujeto que es el campesino de la agricultura tradicional, que mismo con la hegemonía en el MST ser por la Revolución Verde en el periodo, una base social del Movimiento mantiene la 
agricultura tradicional, que se apropia parcialmente del paquete de la revolución verde y mantiene una serie de prácticas tradicionales. Entonces es una realidad bastante compleja y contradictoria dentro del MST. En el año 2000 no, allí el Movimiento define por la agroecología como una política nacional, entonces sale del Congreso con esa definición y el desafío inmediato: para impulsar la agroecologiaa es necesario tener técnicos iy dónde están los técnicos? No existen. Quien trabajaba con agroecología como técnico en Brasil eran básicamente los sectores que estaban en las ONGs. Entonces el Movimiento dijo 'vamos crear las escuelas', y ahí comienza los cursos técnicos de nivel secundario [o terciario] de agroecología, en 2001, 2002. Los cursos técnicos van siendo creados, el Sector de Producción, Cooperación y Medio Ambiente es el que tiene la responsabilidad de estructurar esas escuelas. En ese mismo proceso el Movimiento está como miembro de La Vía Campesina Internacional, entonces allí también se discute la agroecología. Y van desdoblándose una serie de acciones y La Vía Campesina entonces conforma un acuerdo que se materializa en un protocolo, que fue firmado en enero de 2005 en el Foro Social Mundial (FSM) en Porto Alegre, entonces allá en el Foro fue realizado un gran acto político en el asentamiento de Tapes en Rio Grande do Sul, como parte de la programación del FSM, y allí se firma el protocolo. El presidente Hugo Chávez, el gobernador de Paraná, el Ministro de Desarrollo Agrario (MDA) el rector de la Universidad Federal de Paraná (UFPR) y un dirigente de La Vía Campesina Internacional, que fue João Pedro Stédile. El protocolo establecía una serie de actividades de cooperación en el continente, entre éstas, crear dos escuelas de grado universitario de agroecologia, una en Paraná (Brasil) y otra en Venezuela. (J. M. Tardim. Entrevista realizada el 27/07/2010.)

La firma del acuerdo en un asentamiento del MST en la ciudad gaucha (Río Grande del Sur) de Tapes, es también un acto muy representativo, siendo allí, uno de los primeros asentamientos a producir de forma orgánica en todo Brasil.

\section{Procesos productivos de transición agroecológica}

La producción primeramente en Tapes y posteriormente ampliada a otros municipios vecinos del arroz ecológico: Tierra Libre, ${ }^{18}$ es organizada por el Grupo Gestor del Arroz Agroecológico, que tiene como miembros grupos de asentados de la región metropolitana de Porto Alegre, organizados a partir de la COCERGS (Cooperativa Central de los Asentamientos del Rio Grande do Sul) y asesorados por la COPTEC (Cooperativa de Prestación de Servicios Técnicos). La producción orgánica en la región empieza estructuralmente en 1998/1999 (como ya descripto por Rodrigo Lopes que vivía en esta región), de 2004 para 2005 se crea el Grupo Gestor del Arroz.

18 "El arroz Tierra Libre es un alimento puro y saludable. Producido con técnicas agrícolas que garantizan la conservación del medio ambiente, preservan la biodiversidad, sin uso de agrotóxicos y fertilizantes químicos proporcionando más salud y mayor calidad de vida." (MOVIMENTO DOS TRABALHADORES..., 2012, nuestra traducción). 
Actualmente el grupo organiza a 16 asentamientos, localizados en 11 municipios de la región metropolitana de Porto Alegre, básicamente, con 428 familias involucradas, produciendo arroz orgánico y/o en transición agroecológica, ${ }^{19}$ en un área de 3.880, 57 hectáreas (MOVIMENTO DOS TRABALHADORES..., 2012). Además de 41,6 hectáreas de hortalizas y plantas medicinales, y 23,73 hectáreas con producción de frutas. En un área total de 6.695,1 hectáreas en proceso de certificación orgánica (MOVIMENTO DOS TRABALHADORES..., 2013).

La evolución creciente en la participación de más familias y asentamientos en la producción orgánica, es un interesante indicativo de cómo el tema fue tomando forma en las bases del Movimiento, frente al rechazo inicial que los primeros productores sufrieron. Tanto de los grandes productores convencionales, como también dentro del propio MST, demostrando la evolución interna de tal debate frente los distintos matices políticos y tecnoproductivos que cohabitan en las bases del Movimiento. ${ }^{20}$ (Véase en el grafico 1):

Grafico 1- Evolución en porcentaje y en número de familias en el grupo

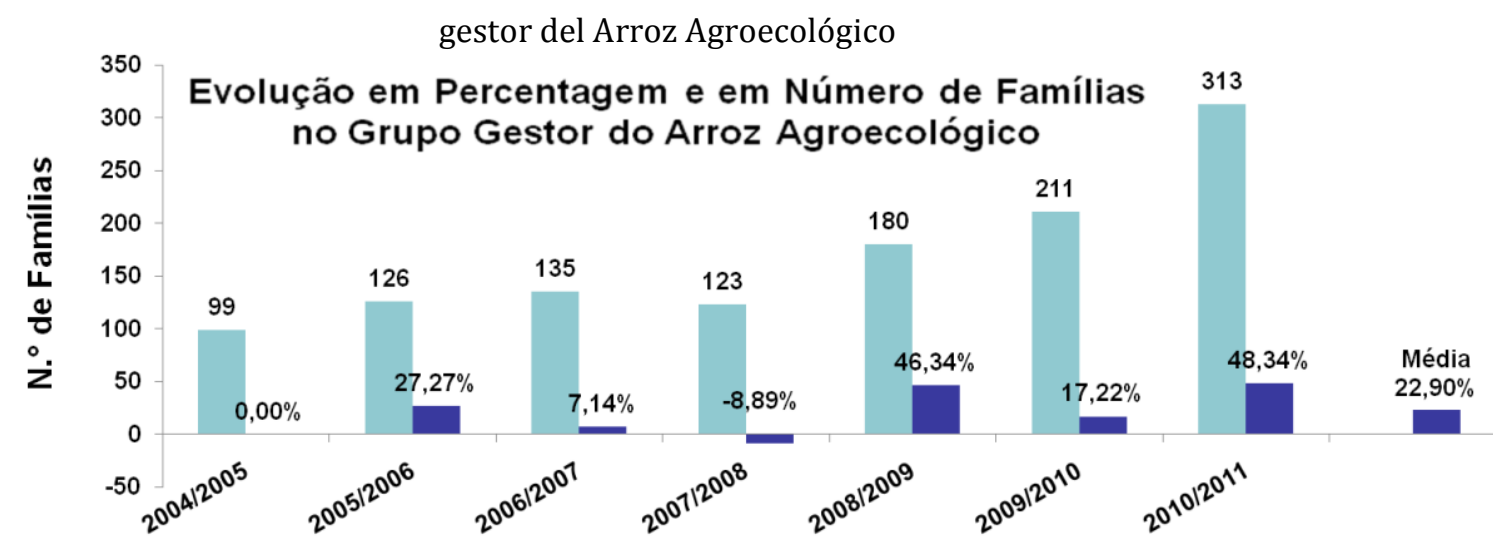

Fuente: Grupo Gestor del Arroz Agroecológico (GRUPO GESTOR..., 2011)

En la cosecha 2010/2011 la producción de arroz agroecológico fue de 150,7 mil sacas, lo que significa 7,5 mil toneladas de arroz, según datos del Ministerio del Desarrollo Agrario (BRASIL, 2011). Parte de las ventas es garantizada por el PNAE (Programa Nacional de Ali-

\footnotetext{
19 "Para la transición agroecológica son necesarios algunos años. Hay necesidad de desintoxicar la tierra y de recuperar e incorporar saberes tradicionales, técnicas y tecnologías, lo que también exige cierto tiempo de aprendizaje y formación. El trabajo humano y las técnicas manuales, por lo menos en parte, precisan sustituir las pesadas maquinas. La posibilidad de generación de renta ni siempre es inmediata, sobretodo comparada a los cultivos convencionales. Parece residir ahí uno de los motivos de resistencia de muchos asentados. La necesidad de mayor tiempo y cuidados, en contraposición a la facilidad que el uso de agrotóxicos y de maquinarias y el monocultivo posibilitan, es reconocidamente una de las razones de la resistencia." (SCHEREINER, 2012, p. 11, nuestra traducción).

20 "En el inició cuando nosotros comenzamos a producir arroz el grupo de arroz ecológico era muy chico, y atacado por todos lados. Nosotros bromeábamos que éramos contra 'todo y contra todos' y contra algunos de nosotros mismos. Que incluso los compañeros rotulaban... Después fue creciendo lentamente ese grupo.” (Rodrigo Lopes. Entrevista realizada el 29/07/2010)
} 
mentación Escolar) y es comprada por intendencias municipales con recursos de tal programa federal, donde 30\% de toda la merienda escolar debe ser adquirida desde la agricultura familiar, y en éste caso específico desde la producción orgánica y/o en transición agroecológica.

No sólo el arroz, sino hortalizas y leguminosas también son distribuidas por el programa, alimentos producidos en los mismos asentamiento del arroz, pero en una escala familiar (el arroz es producido colectivamente en espacios que reúnen núcleos de producción que trabajan y venden en forma cooperada), recolectado en cada familia y distribuido por las distintas municipalidades, para programas de auxilio a la alimentación a familias carentes PAA (Programa Nacional de Adquisición de Alimentos) y/o a la ya referida merienda escolar.

Parte de los asentamientos ya cuentan con certificaciones, nacional e internacionales (de Estados Unidos y Unión Europea) que garantizan el origen y la posibilidad de vender el producto como orgánico. Sin embargo, Rodrigo Lopes defiende que aún con las certificaciones que garantizan la llegada del producto al rico mercado verde de las clases medias "esclarecidas" no es este el objetivo principal de la producción agroecológica de los asentamientos. Contrastando luego con las visiones ecoeficientes que miran en la producción orgánica, a un mercado a ser explotado en vistas a la obtención de mayor ganancia:

\begin{abstract}
Nosotros tenemos orgullo de estar entregando, principalmente para merienda escolar, porque nosotros estamos dando lo que hay de mejor en termos de alimentación para nuestros niños... [...] Con todo el respeto que nosotros debemos tener por las personas esclarecidas, que hacen su opción por alimentarse de manera más saludable, y es un derecho de ellas, pero ellas también podrían estar pagando más barato si no hubieron sido creadas esas industrias del capitalismo verde. Entonces para nosotros campesinos producir orgánicamente y con respeto al medio ambiente debe estar en nuestra visión de mundo, la idea que tenemos de producir con preocupación ambiental no es porque voy ganar más dinero, pero porque quiero vivir mejor, ¿por qué nosotros dejamos de usar veneno? Porque estábamos enfermos, éramos un asentamiento en una comunidad enferma. Es eso que queremos, para nosotros campesinos la idea que trabajamos es: si alguien llega a mi casa para comer yo no le voy ofrecer comida con veneno. (Entrevista realizada el 29/07/2010)
\end{abstract}

En los relatos de Rodrigo las diferencias entre las propuestas y objetivos de un movimiento social como el MST, frente a los productores orgánicos tradicionales generalmente vinculados a un ambientalismo de resultados (ACSERALD, 2012) en los marcos del llamado capitalismo verde, demuestran muchas veces sus posiciones antagónicas, en las contradictorias perspectivas económicas y ambientales en juego: 
Los productos orgánicos tiene un precio sobrevalorado, en algunos productos se justifica porque exige un costo de producción más elevado porque la productividad es más baja, en el caso del arroz la proporción es totalmente inversa, en el arroz nosotros producimos con la misma productividad del arroz convencional con 30\% menos de gastos. Entonces en tesis la producción agroecológica de arroz debería bajar el costo de producción, debería bajar el precio final al consumidor, pero no baja. Nosotros circulamos allí en el medio de los productores orgánicos de arroz y somos los malditos en el medio, porque ellos quieren vender el arroz a $\mathrm{R} \$ 7,00$ reales [\$3,52 USD] el quilo y nosotros entregamos el arroz aquí en São Paulo a $\mathrm{R} \$ 2,00$ reales [\$1,01 USD] (precios del 2013) el quilo, orgánico. Entonces nosotros somos los malditos, a las personas no les gusta nuestra actitud, los productores orgánicos tradicionales no les gusta los asentados sin tierra... El arroz de mi asentamiento tiene 3 certificaciones una brasilera, otra europea y una norteamericana. Nosotros somos la única industrial de arroz certificada en Brasil, ¿cuál es la lógica? Normalmente certifican el cultivo, pero en la hora de pasar por la industria, el arroz va pasar por los mismos equipos, por la misma maquinaria que empaqueto el arroz convencional y el transgénico, entonces puede haber contaminación. En nuestra industria de arroz jamás pasó un único grano de arroz que tenga recibido veneno. Nosotros vendimos y entregamos arroz, ahora, terminamos de firmar una entrega de arroz a la municipalidad de São Bernado do Campo [región metropolitana de São Paulo] para la merienda escolar a $\mathrm{R} \$ 2,61$ reales [\$1,31 USD] el quilo. Eso por cuenta del costo de transporte, pero el productor ecológico que quiere vender arroz a $R \$ 7,00$ reales el quilo, o hasta $R \$ 12,00$ reales [\$6,04 USD] dependiendo de la variedad del arroz como vemos por ahí, ellos nos odian... (Rodrigo Lopes. Entrevista realizada el 29/07/2010)

En ese sentido también el proceso de implementación de la agroecología en la práctica productiva de determinados campesinos de la agricultura familiar, realizado en el ámbito de los proyectos de formación de algunas ONGs es definido como limitado, desde la perspectiva del MST. En las cartillas de las ONGs muchas veces aparecen el combate puntual contra la utilización de los transgénicos, pero no hay una real intención en definir las bases de la estructuración de tal modelo productivo, desde una perspectiva que lleve en cuenta los distintos intereses en disputa en el debate sobre el modo de producción convencional. Las ONGs tienden a reproducir una visión ecológica (ambientalista) más vinculada a la idea de que en el debate ambiental, no hay, o mismo que tal debate ya ha superado las cuestiones relativas a las disputas de intereses entre diferentes clases sociales (PINTO, 2011).

Ya en la perspectiva que surge desde el MST la propuesta agroecológica es entendida adentro de la constitución de un proyecto político para la sociedad, asimilada a su fundacional lucha por la reforma agraria. Así los actores sociales propugnadores de los transgénicos enmascarados en el seno de las "modernas" propuestas del agronegocio, son entendidos 
como representantes políticos de un proyecto de sociedad que inviabiliza la realización de la agroecología en una escala que supere a las aisladas experiencias puntuales.

[Para nosotros la agroecología] es un proyecto de transformación de la sociedad, para ellos [ONGs] no está puesto esto. Cuando tú ves los programas de formación que las ONGs desarrollan con los campesinos [...] Hay la dimensión política, por ejemplo, luchar contra los transgénicos ellos proponen, ahora analizar quien es la Monsanto del punto de vista del capital y el campesino frente a ella no se hace. Entonces queda una cosa mágica y el campesino por sí sólo no alcanza, él no alcanza percibirse ahí, con raras excepciones, la mayoría de ellos también termina no percibiendo, por eso acaban siendo conducidos por las ONGs. Mismo que el discurso de las ONGs no puede reconocer, las ONGs hacen ese discurso de lo participativo democrático, pero la conducción de la visión de mundo y de la acción en el mundo que el campesino ligado a ella hace, es conducido por la ONG. (J. M. Tardim. Entrevista realizada el 27/07/2010.)

Las experiencias realizadas por el MST/Vía Campesina son de orden puntual (internamente en el Movimiento y principalmente en relación a las necesidades productivas de toda la sociedad), por más que la agroecología sea hoy la corriente político-productiva hegemónica adentro de las filas del MST (por lo menos como discurso en las plataformas políticas), apareciendo en los documentos y comunicados oficiales, además de haber una concreta y creciente producción (como del arroz descripto anteriormente) agroecológica. No es la agroecología, sin embargo, la única corriente productiva seguida por los asentados de los distintos territorios del Movimiento, de hecho según los propios entrevistados la mayor parte de la producción realizada en los asentamientos del MST es todavía convencional (en muchos casos incluso soja transgénica), sea por las dificultades técnicas y económicas de la realización de una transición agroecológica muchas veces ya en marcha, sea por una decisión colectiva/subjetiva en no adoptar tal forma de producción en los asentamientos.

En los distintos relatos y documentos analizados, vemos que la implementación en la esfera discursiva de la agroecología, a partir de la mayor visibilidad y efectividad del debate ambiental en el Movimiento de los Sin Tierra, refleja por un lado el proceso interno que a lo largo de los años fue demostrando los límites ambientales y económicos del modo de producción convencional, y por el otro, la necesidad de nuevas estrategias de resistencia para la agricultura campesina frente el ascenso de los transgénicos y la ofensiva del agronegocio.

$\mathrm{Al}$ contrario de lo que es generalmente previsto como regla, el proceso de adopción de la agroecología no necesariamente nace como un anhelo y direccionamiento político bajado transversalmente desde los liderazgos, técnicos e intelectuales orgánicos del Movimiento. En algunos casos como de las primeras experiencias orgánicas que pretendían ser 
de mayor productividad (escala), ocasionando mayor riesgo por la incertidumbre que una forma de producción todavía desconocida y/o subvalorada representaba; tales experimentos no eran recomendados por ciertos sectores técnicos del Movimiento, frente la hegemonía impuesta por los métodos de producción convencionales.

Esta divergencia interna refleja por un lado la necesidad de producir un cambio en la matriz productiva en el interior del MST, surgida de las dificultades materiales enfrentadas en la propia base, por cuestiones económicas y de contaminación de los productores. Mientras que la negativa-inicial- de los sectores técnicos del MST en no recomendar tal práctica, demostraba la reproducción ideológica muchas veces tácita- también desde las concepciones políticas y por la formación técnica recibida- de los supuestos beneficios del modo de producción dependiente de venenos, mucha maquinaria y rehén del mercado de los commodities que presionaba por la no adopción de la agricultura orgánica y posteriormente agroecológica.

La aceptación de la agroecología como debate nacional, adoptada programáticamente por el Movimiento desde su $4^{\circ}$ Congreso Nacional en el año de 2000, tampoco refleja un asentimiento unívoco en relación a la agroecología, que aún es una experiencia en desarrollo, muchas veces subestimada por grandes parcelas del Movimiento, que todavía no creen ser la misma efectiva en relación a las metas esperadas en la productividad. Además del cambio de manejo que implica, obligando a que muchos campesinos vuelvan a ejercer un más frecuente contacto con la labranza, en la retomada de algunas prácticas manuales en detrimento del elevado uso de maquinaria vinculado al proceso convencional, que utiliza además un alto grado de agrotóxicos y fertilizantes químicos.

A todos los debates políticos y técnicos anteriormente descriptos, se suma también la influencia de las legislaciones ambientales vigentes, que reproduciendo la colonial asimetría jurídica brasileña, tiende a culpabilizar a las camadas más bajas de la sociedad, y casi nunca las grandes industrias y haciendas, de los llamados crimines ambientales. ${ }^{21}$ Así muchos sectores del Movimiento fueron obligados por ley, (mediada por el INCRA órgano federal responsable por el auxilio y fiscalización de los asentamientos), a no producir con insumos químicos.

Tal proceso según miembros del Movimiento genera otras contradicciones que, no obstante, son vistas como positivas para el avance del debate interno. Una característica pa-

21 Para ampliar la perspectiva sobre las inequidades presentes en la aplicación de la legislación ambiental brasileira véase Pinto y Carneiro (2012). 
tente en el proceso de obligatoriedad del uso de insumos orgánicos, en determinados territorios, es la idea subyacente a la argumentación relatada en las entrevistas con miembros del movimiento, de que no basta producir con el cambio de insumos, pero usando la misma lógica del monocultivo, sin entender por lo tanto el real significado político de lo que están haciendo. Representando tal perspectiva una muestra del tipo de debate ambiental que un movimiento social históricamente vinculado a los debates sobre la justicia social, va consecuentemente haciendo, a diferencia de ONGs, empresas privadas y políticas ambientales preocupadas solamente con una reificada y mercantilizada defensa abstracta de la "naturaleza".

En otro proceso vinculado a la implementación de la agroecologia en territorios del MST, en este caso en el estado del Paraná (también en la región sur de Brasil) en el municipio de Lapa, en el Asentamiento Contestado donde además de la experiencia interna de los propios asentados, también se va instalar la Escuela Latinoamericana de Agroecología (ELAA). En lo referente a los debates sobre la producción orgánica hubo tensiones desde la implementación del Asentamiento (en 1999), donde por deliberaciones internas, y mismo por una cuestión de legislación ambiental, parte del área total tendría que ser preservada. Hubo entonces la decisión de producir de forma orgánica (sin insumos químicos) entrando tal ítem incluso en el reglamento interno del asentamiento, hecho que llegaría posteriormente a influenciar en la elección del asentamiento Contestado como sede de la Escuela Latinoamericana de Agroecología, como nos fue explicitado por el director político pedagógico de la ELAA, Tardim durante la entrevista ya citada.

Por lo tanto, desde la perspectiva de Antonio Capitani, miembro del MST que participó desde el principio de la construcción del asentamiento Contestado (viví allí todavía y es reconocido como uno de los referentes del asentamiento) y acompaño internamente los debates y conflictos vinculados a la transición agroecológica en entrevista con él pudimos vislumbrar más de cerca los procesos y problemáticas culturales y de hábitos arraigados y explicitados en los procesos de ambientalización de los modos de producción en territorios del MST.

A diferencia del caso anteriormente descripto y debatido de la producción del Arroz Agroecológico en Rio Grande do Sul, parece que en el caso del asentamiento Contestado, en Paraná, las deliberaciones políticas del MST provincial, aliadas a las convicciones de parte de los asentados en favor de la implementación de la producción orgánica, en un momento donde el Movimiento mismo no tenía estructura para resguardar técnica y políticamente tal 
experiencia, (a partir de 1999) ha sido parte de los motivos que generaran conflictos internos relativos al modo de producción adoptado por el asentamiento, y por ende, no aceptados por todos sus miembros, conflictos presentes hasta la actualidad.

No sólo en sus bases- en los territorios productivos del Movimiento- el proceso de transición agroecológica está en constante debate y todavía no es asumido mayoritariamente en las prácticas productivas, sino que también desde de partes de la dirección (más allá de las decisiones políticas consensuadas en los documentos oficiales), es un debate que todavía encuentra cuestionamientos y no es abiertamente defendido por todos los miembros de un movimiento social tan grande y complejo como el MST.

\section{Consideraciones finales}

Las dinámicas presentes en los procesos de ambientalización de los conflictos sociales (LOPES, 2002; PINTO, 2013) dejan claro la complejidad de tal fenómeno. La asimilación de la variable ambiental en el cuerpo de sus históricas propuestas de reforma agraria y justicia social para el Brasil (influenciadas inicialmente y posteriormente revertidas hacia el interior de las organizaciones miembro de La Vía Campesina), fue fruto de necesidades materiales directas, decisiones políticas coyunturales y la influencia de demás movimientos agrarios y ambientalistas vinculados a La Vía Campesina Internacional y los debates agroecológicos en general. Asimismo, tal decisión más allá de abrir una nueva perspectiva en relación a los aspectos productivos instaurados en la propuesta agroecológica, por ésta misma naturaleza, rescata como válidos (ya no más como retrasados) a los procesos y prácticas productivas que su base campesina tradicional trae en la memoria social y simbólica, anteriores a la hegemonía de la revolución verde.

En tales debates a partir del surgimiento del agronegocio 22 en un contexto crecente de concentración de tierra y renta, la propuesta agroecológica presente en la idea de soberanía alimentaria pasa a representar cada vez más no sólo un avance organizativo interno del Movimiento, y una adecuación a los más recientes debates sobre el calentamiento global, sustentabilidad, reciclaje... tan de modas. Más bien encarna la posibilidad de pensar un proyec-

\footnotetext{
22 “Incentivado por el gobierno [Lula] el agronegocio tiene como lógica la explotación de la tierra, de los recursos naturales y del trabajo, por medio del financiamiento público. No produce alimentos para el pueblo brasilero, deteriora el ambiente, gen era pocos empleos y utiliza grandes extensiones de tierra para los monocultivos de exportación, basados en bajos sueldos, uso intensivo de agrotóxicos y de semillas transgénicas. En un contexto de crisis económica mundial, no hay condiciones de producir para las poblaciones o crear puestos de trabajo para los agricultores." (MOVIMENTO DOS TRABALHADORES..., 2010, nuestra traducción).
} 
to distinto de agricultura para el país, que pase a representar un real cuestionamiento y alternativa al proyecto de agricultura actualmente hegemónico. ${ }^{23}$

Así en los actuales conflictos por la tierra en Brasil, principalmente los que tienen como protagonistas a los movimientos vinculados a la sección brasileña de La Vía Campesina, desde los afectados por represas hidroeléctricas (Movimiento de Afectados por Represas MAB en portugués), hasta las clásicas disputas territoriales entre los sin tierra y las elites agrarias y los inversionistas del agronegocio, dos formas (por lo menos) de intervención en los biomas y agroecosistemas están en disputa, lo que podríamos nombrar de conflictos ambientales. Que no dejan de ser conflictos epistemológicos, culturales e históricos de concepciones en busca de legitimidad.

\section{Agradecimientos}

El autor agradece a la UNAM, al Programa de Becas posdoctorales en la UNAM, por ser Becario del Centro de Investigaciones interdisciplinarias en Ciencias y Humanidades (CEIICH-UNAM) actualmente, también el Consejo Nacional de Investigaciones Científicas y Técnicas (CONICET) Argentina y al Centro de Estudios de la Argentina Rural de la Universidad Nacional de Quilmes (CEAR-UNQ) por el apoyo durante el desarrollo de la tesis doctoral, cuando he realizado parte del trabajo de campo del presente artículo.

\section{Referencias}

ACSELRAD, Henri. 'Descaminhos do 'ambientalismo consensualista'. Revista del Observatorio Social de América Latina, Buenos aires, v. 12, n. 34, p. 39-50, nov 2012.

AMIN, Samir. Capitalismo, imperialismo, mundialización. In: SEOANE, José; TADDEI, Emilio. Resistencias Mundiales. De Seattle a Porto Alegre. Buenos Aires: CLACSO, 2001. p. 15-19

\section{ARCEO, Enrique. El fin de un peculiar ciclo de expansión de la economía norteamericana. La crisis mundial y sus consecuencias. Buenos Aires: IEC, 2009.}

BORGES, Juliano Luis. MST: do produtivismo a agroecologia. In: SEMINÁRIO NACIONAL SOCIOLOGIA \& POLÍTICA, 1., Curitiba, 2009. Anais... Curitiba: UFPR, 2009. Disponível em <http://www.humanas.ufpr.br/site/evento/SociologiaPolitica/GTsONLINE/GT7\%20online /mst-produtivismo-JulianoBORGES.pdf>. Consultado en: 14 nov. 2015.

\footnotetext{
23 "Hoy la agricultura brasilera es disputada claramente por dos proyectos. Un patrocinado por el agronegocio y las transnacionales. El otro, reivindicado por los movimientos sociales, defiende la agricultura familiar, la biodiversidad y la naturaleza. […] Ya sabemos las enormes y graves consecuencias que el agronegocio trae para la clase trabajadora del campo y para toda la sociedad brasilera. Bajo control de las transnacionales, producen sólo para exportaciones y dispensan mano de obra. Eso sin hablar en el trabajo esclavo y en la destrucción permanente de la biodiversidad. El fruto de esta situación es que más de 300 mil trabajadores y trabajadoras fueron expulsos de las áreas rurales." (JORNAL SEM TERRA, 2006 apud Borges, 2009, p. 17, nuestra traducción).
} 
BRASIL. Ministério do Desenvolvimento Agrário. Assentados do RS colhem 7,5 mil toneladas de arroz ecológico. Brasília: MDA, 2011. Disponível em:

<http://www.mda.gov.br/sitemda/noticias/assentados-do-rs-colhem-75-mil-toneladas-dearroz-ecol\%C3\%B3gico>. Acesso em: 24 nov. 2015.

BRUNO, Regina. Agronegócio e novos modos de conflituosidade". In: FERNANDES, Bernado M. (Org.) Campesinato e agronegócio na América Latina: a questão agrária atual. São Paulo: Expressão popular, 2008.

COSTA NETO, Canrobert; CANAVESI, Flaviane. Sustentabilidade em assentamentos rurais: o MST rumo à reforma agrária agroecológica no Brasil? In: ALIMONDA, Héctor (Org.).

Ecologia Política. Naturaleza, sociedad y utopía. Buenos Aires: CLACSO, 2002. p. 203-215

CARVALHO, Horácio Martins. La emancipación del movimiento en el movimiento de la emancipación social continúa. Respuesta a Zander Navarro. In: SANTOS, Boaventura de Sousa. Producir para vivir. Los caminos de la producción no capitalista. Ciudad de México: FCE, 2011.

MARTINEZ ALIER, Joan. El ecologismo de los pobres: Conflictos ambientales y lenguajes de valoración. Barcelona: Icaria. 2009.

MOVIMENTO DOS TRABALHADORES Rurais Sem Terra. Cooperativa de Prestação de Serviços Técnicos. [Folheto informativo]. [S,l.], 2013.

GRUPO GESTOR do Arroz Agroecológico. Programa de arroz agroecológico 2009-2011. [S.l.], 2011. 1 apresentação power point. Apresentado ao Instituto Nacional de Colonização e Reforma Agrária (INCRA).

LOPES, José Sergio Leite. Introdução. In: LOPES, José Sergio Leite (Org.). Ambientalização dos conflitos sociais. Participação e controle público da poluição industrial. Rio de Janeiro: Relume Dumará, 2004. p.17-38

MORISSAWA, Mitsue. A história da luta pela terra e o MST. São Paulo: Expressão Popular, 2008.

MOVIMENTO DOS TRABALHADORES Rurais Sem Terra. Lutas e Conquista. Reforma agrária: por justiça social e soberania popular. São Paulo: Secretaria Nacional do MST, 2010.

MOVIMENTO DOS TRABALHADORES Rurais Sem Terra. Jornal Sem Terra, [S.l.], n. 318, mar./maio, 2012.

MOVIMENTO DOS TRABALHADORES Rurais Sem Terra. A cooperação agrícola no MST. [S.l.], 2009. Disponível em: <http://antigo.mst.org.br/node/8605>. Acesso em: 24 nov. 2015.

NAVARRO, Zander. 'Movilización sin emancipación'. Las Luchas sociales de los sin tierra en Brasil. In: SANTOS, Boaventura de Sousa. Producir para vivir. Los caminos de la producción no capitalista. Ciudad de México: FCE., 2011. 
PINTO, Lucas Henrique. La ideología del desarrollo sustentable y la administración simbólica de los conflictos ambientales: relación entre los aparatos ideológicos de Estado y la ecoeficiencia. In: CERDÁ, Juan Manuel; LEITE, Luciana. (Ed.). Conflictividad en el agro argentino. Ambiente, territorio y trabajo. Buenos Aires: CICCUS, 2011a. p. 121-241.

PINTO, Lucas Henrique. La globalidad de la lucha anti-globalización: interdependencia económica mundial y procesos de resistencia campesina en un mundo globalizado. Notas sobre la experiencia de La Vía Campesina. Cuadernos 39, San Salvador de Jujuy, 2011b. Suplemento.

PINTO, Lucas Henrique; CARNEIRO, Eder Jurandir. Conflitos ambientais na microrregião de Barbacena (Minas Gerais, Brasil): o que as fontes permitem ver? Estudios Rurales.

Publicación de Centro de Estudios de La Argentina Rural, Bernal, v. 1, n. 2, p. 44-64, 2012.

PINTO, Lucas Henrique. Trayectorias de la Reforma Agraria en América Latina, de política pública y consigna revolucionaria a una demanda ecologista: esbozos de un análisis teóricoconceptual. In: SALOMÓN, Alejandra; RUFFINI, Marta. Estado, ciudadanía y políticas públicas. Rosario: Prohistoria, 2013. p. 135-158

PINTO, Lucas Henrique. La influencia de la Comisión Pastoral de la Tierra (CPT) en la formación del Movimiento de los Trabajadores Rurales Sin Tierra (MST): breve análisis teórico-documental del papel de la religión en los conflictos sociales en Brasil. (1954-1984). Revista Estudios Sociales, Bogotá, n. 51, pp. 76-88, 2015.

SAMPAIO, Plínio de Arruda. Os períodos da história do Brasil. In: SAMPAIO, Plínio de Arruda; STEDILE, J.P. (Org.) História crise e dependência do Brasil. São Paulo, 2000. p. 823

SCHREINER, Davi F. Territorialidades em disputa. Os assentamentos, o MST e a luta coletiva. Mendoza: Jornadas Internacionales de Problemas Latinoamericanos, 3., Mendoza, 2012.

Actas... Mendonza, 2012.1 CD-ROM.

STEDILE, Joao Pedro. A raiva das elites. 0 Dia, [S.I.], maio 2010. Disponível em: <http://antigo.mst.org.br/node/9784>. Acesso em: 15 abr. 2010.

WAGNER, Lucrecia; PINTO, Lucas Henrique. Ambientalismo(s) y bienes naturales: desafíos al extractivismo, en Argentina y Brasil. Revista Letras Verdes, Quito, n. 14, p. 69-94, 2013. Dossier Minería, Ambiente y Movimientos Sociales. 


\title{
Processos de ambientalização e transição agroecológica no MST: reforma agrária popular, soberania alimentaria e ecologia política.
}

\section{Resumo}

Procuraremos analisar no presente artigo como a hegemonia do projeto neoliberal na economia mundial e as mudanças produtivas do regime capitalista, levaram ao Movimento dos Trabalhadores Rurais Sem Terra (MST) a incrementar também suas bandeiras, tanto pelos avanços oriundos dos conflitos organizativos internos como também pela sua adequação as novas conjunturas hegemônicas. Problematizaremos estes processos interacionando a nova forma de pensar a reforma agraria com alguns pontos da chamada questão ambiental, que não é segundo nossa hipótese, somente uma assimilação de um assunto atualmente de moda, senão é a incorporação de um aspecto central no debate sobre o atual estagio produtivo das forças capitalistas e as externalidades produzidas nos processos de produção de mercadoria. Questões que discutiremos a partir de entrevistas com membros do Movimento e suas impressões sobre as dinâmicas de tais processos de ambientalização e transição agroecológica.

\section{Palavras-chave}

Ambientalização. MST. Agroecología. Ecologia política. Reforma agraria.

\section{Process of Environmentalization and ecological agrarian transition in MST: agrarian popular reform (food sovereignty and ecologic politics)}

\begin{abstract}
The present text aims to analise the sovereignty of the world's neoliberal economic project and the productive changes of the capitalist regime which led the MST to reinforce their own mottos, both for the advances provided by the internal organization conflicts and adaptions for the new hegemonic conjuncture. We are going to problematize these process and interrelating the new way of thinking about land reform with some aspects of the environment issue, which in our hypothesis it is not just a trending topic, but it is a central and important subject of the current debate about the capitalist forces of
\end{abstract}


production and the external elements produced by the process of production of goods. Then we are going to problematize some subjects from interviews with MST members and their impressions about the process of Environmentalization and ecological agrarian transition.

\section{Keywords}

Environmentalization. MST. Agrarian ecology. Ecology politics. Land reform.

Recebido em 04/09/2015

Aceito em 07/12/2015 